\title{
Design Description of a Stand-Alone, Auto-Frequency Ultrasonic Brand of Weaver Bird Pest Control Device for Field Applications
}

\author{
A.G Ibrahim ${ }^{\mathrm{a}^{*}}$, O.D Oyedum ${ }^{\mathrm{b}}$, O.B Awojowogbe \\ ${ }^{a, b, c}$ Department of Physics Federal University of Technology, Minna, Nigeria.
}

Received: 19 April 2017; Accepted: 13 May 2017; Published: 08 September 2017

\begin{abstract}
Preliminary studies conducted in the field of ultrasonic broadcast for bird pest control has identified among others, that ultrasound of specific frequencies and certain audio sounds can serves as effective parameters in weaver bird pest scaring. Of interest is ultrasound frequency of $35 \mathrm{kHz}$ as the put-to-flight and stay-away frequency in bird homes, while $25 \mathrm{kHz}$ holds in farm conditions. These findings set the stage for this work which is aimed at determining the compositions, dimensions and specifications of a stand-alone device capable of electronically generating ultrasound of the required frequencies and incorporating audio sounds of predators to effectively scare weaver birds away from farms while overcoming the challenge of habituation. The design consists of sections as: the solar power supply, tripping, timing, oscillatory, frequency selection, amplification, microcontroller, predator cry, LCD and ultrasonic transducer sections and their respective circuits. The design if implemented and tested, will ensure $360^{\circ}$ horizontal ultrasound coverage and a vertical boost to effectively repel weave bird pests from the vicinity of broadcast.
\end{abstract}

Index Terms: Ultrasound, stand-alone device, design considerations, integrated circuit (IC), habituation, weaver birds.

(C) 2017 Published by MECS Publisher. Selection and/or peer review under responsibility of the Research Association of Modern Education and Computer Science.

\section{Introduction}

Electronic pest control devices are electronically designed devices used to keep away pests from vicinity where they are deployed. They have the advantage of being safe, cheap, environmentally and ecosystem friendly [1], especially when compared with chemical pest control method [2]. However, controversies trail its application, as they are regarded as being effective [3], partially effective [4] and ineffective [5]. Habituation was identified as the sole reason for this controversy [6]. Design considerations and practices to technically

* Corresponding author. Tel. +2348062382666

E-mail address: ibrahimaku@ futminna.edu.ng 
fortify the device against habituation were proffered and prominent among them was field survey [6]. The common practice whereby electronic pest control devices were purchased off the shelf and deployed to combat pests, but no sooner than they are installed than they become ineffective, was discouraged and specialized field survey (preliminary studies) was recommended [7]. In view of the foregoing, an intensive field survey comprising the assessment of ultrasonic bird flight data was carried out and a put-to-flight frequency of $35 \mathrm{kHz}$ was obtained [8], as well as the assessment of the ultrasonic bird return data to obtain the stay away frequency which coincidentally was also $35 \mathrm{kHz}$ [9], and the farm test data to obtain the farm safety threshold of $25 \mathrm{kHz}$ [10]. In this current work, the findings of the field survey $[8,9,10]$ were technically taken into consideration in designing an independently operated device that can effectively combat the menace of weaver bird pest infestation.

\section{Design Description}

The functional sections of the proposed design were grouped into ten sections and each section elaborately discussed in terms of design considerations, design calculations, component specifications and circuit diagrams. The block diagram of the design is shown in Fig. 1.

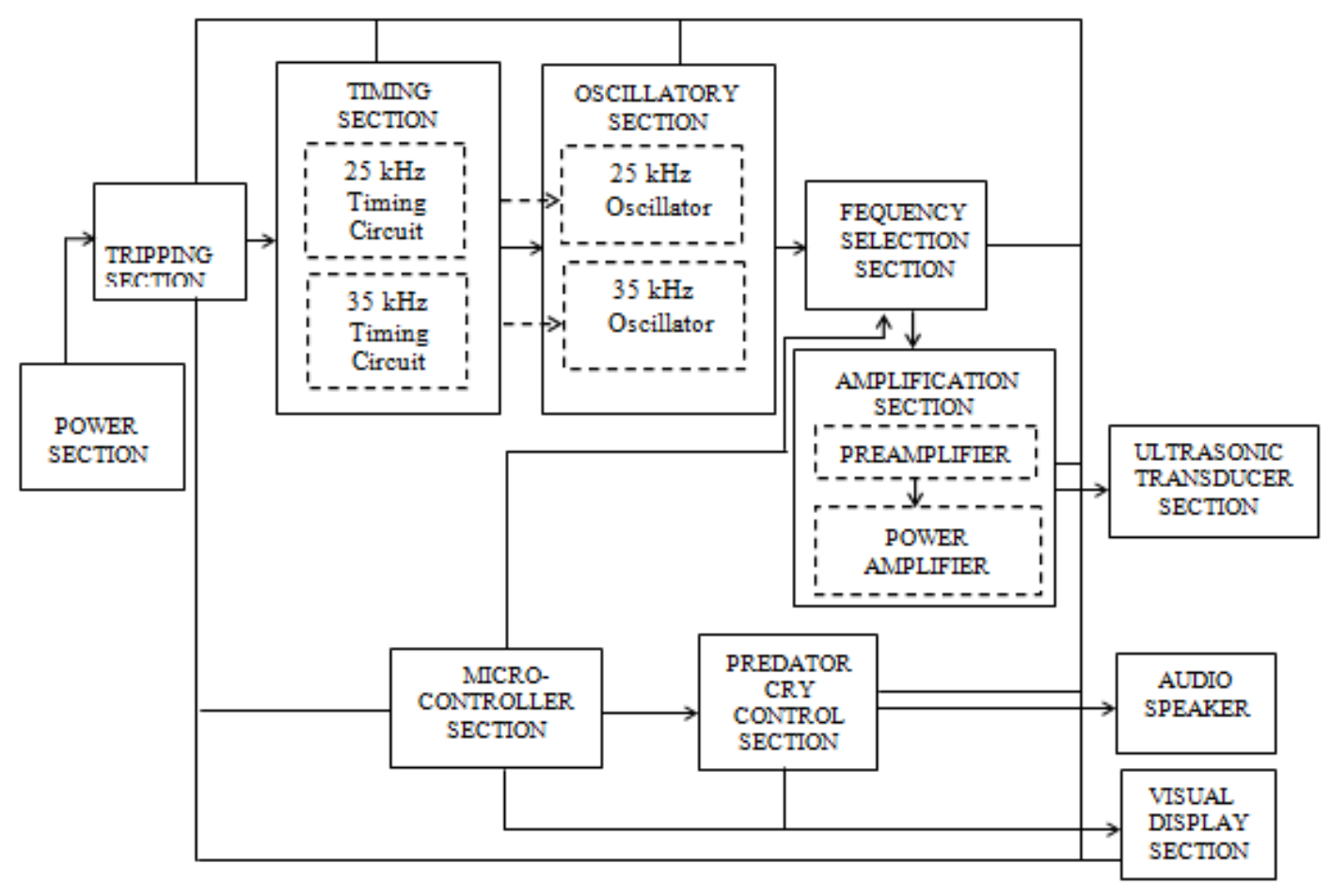

Fig.1. Block diagram of the Design

These sections are discussed serially below.

\subsection{Power Section}

The power section is a unit capable of supplying dc voltage and current to an electronic circuit under test 
[11]. For this design, the abundant solar energy potential in the study area was harnessed as a reliable source of power [9]. This section comprises of three constituents, namely: the solar panel, power bank and the solar charge controller.

\subsubsection{Solar Panel}

The enormous renewable energy of the tropical African sun was harnessed using solar panel. Previous research on evaluation of solar panels for use in the study area suggested that polycrystalline solar panel performed better than other types [12]. Therefore, a polycrystalline solar panel with electrical ratings tabulated in Table 1 was used in this design.

Table 1. Electrical Rating of Solar Panel at standard test condition (STC): $\mathrm{E}=1000 \mathrm{Wm}^{-2}, \mathrm{AM}=1.5, \mathrm{~T}_{\mathrm{c}}=25^{\circ} \mathrm{C}$

\begin{tabular}{ll}
\hline Electrical Rating & Values \\
\hline Maximum power $\left(\mathrm{P}_{\max }\right)$ & $50 \mathrm{~W}$ \\
Open circuit voltage $\left(\mathrm{V}_{\mathrm{oc}}\right)$ & $21.5 \mathrm{~V}$ \\
Short circuit voltage $\left(\mathrm{V}_{\mathrm{sc}}\right)$ & $18 \mathrm{~V}$ \\
Short circuit current $\left(\mathrm{I}_{\mathrm{sc}}\right)$ & $3.05 \mathrm{~A}$ \\
Maximum power current $\left(\mathrm{I}_{\mathrm{m}}\right)$ & $2.77 \mathrm{~A}$ \\
Output tolerance $(\%)$ & +3 \\
Operating temperature $\left({ }^{\circ} \mathrm{C}\right)$ & $-40^{\circ} \mathrm{C}-+80^{\circ} \mathrm{C}$ \\
Length $(\mathrm{mm})$ & \\
Width $(\mathrm{mm})$ & 670 \\
Height $(\mathrm{mm})$ & 30 \\
& 4.35 \\
\hline
\end{tabular}

The choice of an $18 \mathrm{~V}$ solar panel was guided by the requirement that a solar panel's electrical specification should be above that of the load it is to feed. In this case, the $18 \mathrm{~V}$ rating of the panel is well above the $12 \mathrm{~V}$ rating of the battery and the succeeding circuitry which has a maximum of $10 \mathrm{~V}$. Also, the power requirement of the circuit which sums up to $10.25 \mathrm{~W}$, which is well below the panels capacity of $50 \mathrm{~W}$. For maximum solar insolation, the solar panel needs to be positioned at the right tilt angle equivalent to the latitude of the location. Niger state, Nigeria is located between latitudes $8^{\circ} 20^{\prime} \mathrm{N}$ and $11^{\circ} 30^{\prime} \mathrm{N}$ and longitude $3^{\circ} 30^{\prime} \mathrm{E}$ and $7^{\circ} 20^{\prime} \mathrm{E}$, while the study area is located about latitude $10^{\circ} \mathrm{N}$ and longitude $6^{\circ} \mathrm{E}$ [13]. Therefore, the solar panel will be tilted at angle $10^{0}$ due south for maximum exposure to solar irradiance at all times of the day. The characterized solar panel [14] with a conversion efficiency of $11.64 \%$, representing $91.7 \%$ of manufacturer's specification is needed to charge a rechargeable battery.

\subsubsection{Power Bank}

A $12 \mathrm{~V}, 7.2 \mathrm{Ah} / 20 \mathrm{hr}$ rechargeable battery which delivers to specification over a 20 -hour period at room temperature serves as the power bank. This choice is due to its power rating and long discharge span. The voltage requirement of the circuit ranges from $5 \mathrm{~V}$ to $10 \mathrm{~V}$ which makes a $12 \mathrm{~V}$ battery sufficient for the design. The battery with an initial current of $1.2 \mathrm{~A}$ is not sufficient to drive a system which weather dependent and subject to future expansion. Therefore, to make up for times of limited solar energy availability like evenings and cloudy days, two of the batteries were connected in parallel. This connection will maintain the $12 \mathrm{~V}$ requirements but boost the current so as not to drain quickly. The battery which is completely sealed, maintenance-free, leak proof and usable in any position has dimension of 6 by 3 by $4 \mathrm{~cm}$. It stores the electrical energy trapped by the solar panel and supplies same to the succeeding section when required.

\subsubsection{Solar Charge Controller}


The power section is furnished with a solar charge controller to monitor the battery by controlling both the solar panel and load. This is necessary since continuous overcharging of the battery would boil the electrolyte dry and ruin the battery. This task was achieved by a 12V, 10 A solar charge controller having a terminal each for a solar panel, battery and load respectively. The choice of $12 \mathrm{~V}$ is to regulate the $12 \mathrm{~V}$ battery to be used, while the $10 \mathrm{~A}$ is much greater than the battery's combined charging current requirement of $2.4 \mathrm{~A}$, a condition for optimum performance. Fig. 2 shows the interrelationship between the parts of the power section.

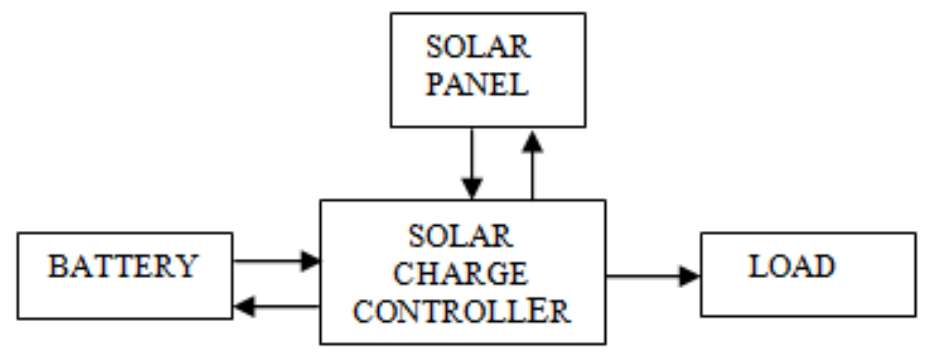

Fig.2. Block Diagram of the Power Section

The charge controllers work by monitoring the battery voltage, and once it reaches full charge (12 V in this case) the controller simply shorts the solar panel leads together to stop further charging. Charging will resume after the battery falls to a discharged voltage of $11.5 \mathrm{~V}$. The solar charge controller also controls the load by disconnecting the load terminal when the battery falls to $10.5 \mathrm{~V}$. The load is isolated to prevent the battery from becoming flat and is reconnected after the battery is charged beyond the threshold. The later, however, can only occur on cloudy days when the solar panels performance is low.

\subsection{Tripping Section}

This section of the design was incorporated to shut down the active and successive sections at certain times of the day. Weaver birds feed gregariously during all the hours of daylight [9]. It is necessary to shut down the device at night and early hours of the morning when intruder birds are not likely. One of the design considerations is the introduction of tripping system [6]. This will help delay habituation (which would result from a continuous operation of the device) and prolongs the service life of the device. The major component in this section is the photo resistor (Light Dependent Resistor) and its associated circuitry. Fig. 3 shows the photo resistive circuit.

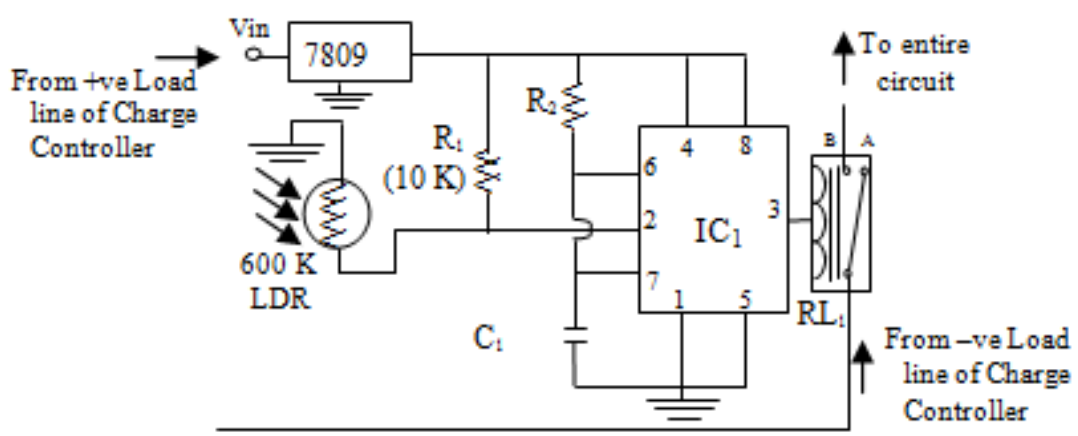

Fig.3. Photo Resistive Circuit 
The associated circuitry comprises of a $600 \mathrm{k} \Omega$ photo resistor and a 555 timer $\left(\mathrm{IC}_{1}\right)$ connected in a monostable mode. In this mode, the 555 timer's output (pin 3) will change state whenever the trigger input (pin 2 ) is excited. The excitation agent here is the photo resistor (Light Dependent Resistor). As light falls on the photo resistor, its resistance drop sharply from $600 \mathrm{~K}$ to below $10 \mathrm{~K}$, the standard value of $\mathrm{R}_{1}$. This change causes the pull up resistor $\left(\mathrm{R}_{1}\right)$ to go low. The role of the pull up resistor of $10 \mathrm{~K}$ is to maintain pin 2 at all time high (i.e at $\mathrm{Vcc}$ ). But the negative going voltage at the input causes the internal components (flip-flops) to toggle leading to a pulse at the output. The timer's output is interfaced to a $6 \mathrm{~V}$ relay $\left(\mathrm{RL}_{1}\right)$ which toggles from position A to B and connecting to the load line of the charge controller to energies the power line with $12 \mathrm{~V}$ which the entire circuit will tap from.

\subsection{Timing Section}

The function of this section is to determine the nature of the output of the oscillator (the succeeding stage) in terms of the frequency of oscillation. Two timing circuits were designed at 25 and $35 \mathrm{kHz}$. The field work conducted in the study area reveals the effective frequency for scaring weaver birds as $25 \mathrm{kHz}$ and $35 \mathrm{kHz}$ from the farms and from their homes respectively [9]. Therefore, both frequencies were generated beginning with their respective timing circuits.

\subsection{1. $25 \mathrm{kHz}$ Timing Circuit}

A $25 \mathrm{kHz}$ timing circuit was designed to frequency tune the oscillator to generate same frequency. The key component of the timing circuit is the timing capacitor $C_{2}$ and timing resistors $R_{3}$ and $R_{4}$. The frequency of operation of the entire circuit is dependent upon the design formula given by,

$$
f=\frac{1}{\left(0.693 \times C_{2} \times\left(R_{3}+2 R_{4}\right)\right)}
$$

Since the circuit is intended to produce a frequency of approximately $25 \mathrm{kHz}$, other parameters can be adjusted to satisfy the rule [15]:

$$
\left(R_{3}+R_{4}\right) \leq 3.3 M \Omega,
$$

with R3 and R4 satisfying:

$$
\left.\begin{array}{l}
R_{3} \geq 1 k \Omega \\
R_{4} \geq 1 k \Omega
\end{array}\right\}
$$

After deciding the operating frequency $(25 \mathrm{kHz})$, it is usual to make $\mathrm{R}_{3}$ about $1 \mathrm{k} \Omega$ because this helps to give the output pulses a duty cycle close to $50 \%$. Thus, choice is made for the values of $\mathrm{R}_{3}$ and $\mathrm{C}_{2}$ as $1.5 \mathrm{~K}$ and 10 $\mathrm{nF}$ respectively. $\mathrm{R}_{4}$ can now be calculated as $2.14 \mathrm{~K}$. Thus, the values of $R_{3}$ and $R_{4}$ satisfy conditions stated in equations (2) and (3) and are within practical limits. The timing network was fine-tuned with a $1 \mathrm{k} \Omega$ variable resistor $\left(\mathrm{VR}_{1}\right)$ which is always turned to very low resistance. This varies the frequency of the output from 20 $\mathrm{kHz}$ to about $30 \mathrm{kHz}$ based on proportionate adjustments. The circuit diagram for the $25 \mathrm{kHz}$ timing circuit combined with the corresponding oscillator is shown in Fig. 4a. 


\subsection{2. $35 \mathrm{kHz}$ Timing Circuit}

The $35 \mathrm{kHz}$ timing circuit is required to keep birds away from their homes located close to the farm [8]. Same equation (1) and (2) used for the $25 \mathrm{kHz}$ timing circuit were used to obtain $\mathrm{R}_{5}, \mathrm{R}_{6}$ and $\mathrm{C}_{3}$ as $1.5 \mathrm{~K}, 1.3 \mathrm{~K}$ and $10 \mathrm{nF}$ respectively. A variable resistor $\left(\mathrm{VR}_{2}\right)$ which is always turned to very low resistance varies the frequency of the output from 30 to about $40 \mathrm{kHz}$. The circuit diagram for the $35 \mathrm{kHz}$ timing circuit combined with the associated oscillator is shown in Fig. 4b.

\subsection{Oscillatory Section}

For this section, the 555 IC known for its versatility was implemented in the astable mode. In this mode, the 555 IC will operate as an oscillator. Thus, two oscillators were designed. The $25 \mathrm{kHz}$ and $35 \mathrm{kHz}$ oscillator which were respectively fed from the 25 and $35 \mathrm{kHz}$ timing circuits.

\subsection{1. $25 \mathrm{kHz}$ Oscillator}

The $25 \mathrm{kHz}$ Oscillator was implemented by $\mathrm{IC}_{2}$, a 555 timer. When in astable mode, both the trigger and threshold inputs (pins 2 and 6) to its two internal comparators will be connected together and to the timing capacitor $\mathrm{C}_{2}$ of the $25 \mathrm{kHz}$ timing circuit. The capacitor charges toward the supply voltage through the two resistors, $R_{3}$ and $R_{4}$ of the $25 \mathrm{kHz}$ timing circuit. Reset input (pin 4) is tied to $V_{C C}$ to avoid any possibility of false resetting. Pin 5 is bypassed to ground with a ceramic capacitor $\left(\mathrm{C}_{4}\right)$ of about $0.01 \mu \mathrm{F}(10 \mathrm{nF})$ for immunity to noise and elimination of false triggering. The discharge pin (pin 7) connected to the internal transistors is connected to the junction of those two resistors as shown in Fig. 4a.

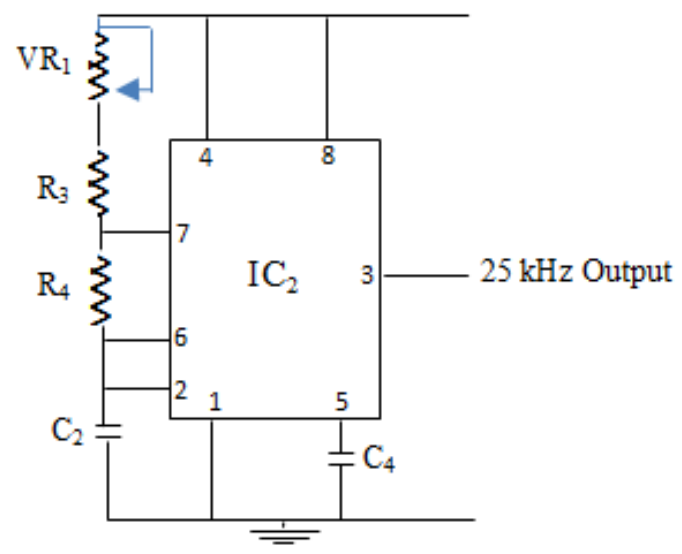

(a) $2525 \mathrm{kHz}$ Oscillator IC in Astable mode

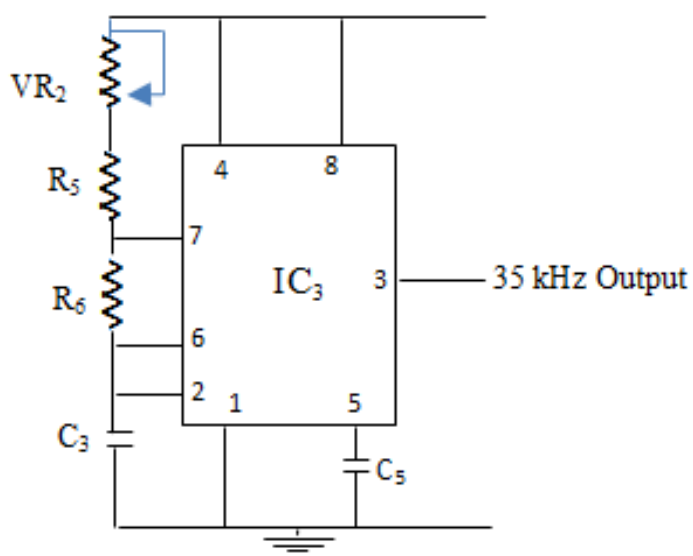

(b) $35 \mathrm{kHz}$ Oscillator IC in Astable mode

Fig.4. (a) $2525 \mathrm{kHz}$ Oscillator IC in Astable mode, (b) $35 \mathrm{kHz}$ Oscillator IC in Astable mode

The alternate charging and discharging of the timing capacitor of the timing section constantly triggers the internal comparators and so cause the flip-flop to be repeatedly set and reset. The resulting output will be a continuous stream of 25,000 rectangular pulses in one second, which explains why this part of the design being called the $25 \mathrm{kHz}$ oscillation section. The period $\mathrm{T}$ of oscillation or time interval between pulses is related to the frequency $f$ by the relation: 


$$
t=\frac{1}{f} 0.69\left(R_{3}+2 R_{4}\right) \times C_{2}
$$

Substituting the earlier obtained values of $R_{3}, R_{4}$ and $C_{2}$ into equation (4) gives the value of the period of oscillation of the device as $40 \times 10^{-6}$ seconds.

\subsection{2. $35 \mathrm{kHz}$ Oscillator}

The $35 \mathrm{kHz}$ Oscillator is equally made up of the 555 timer $\mathrm{IC}\left(\mathrm{IC}_{3}\right)$ also in the astable mode. The timing capacitor $\mathrm{C}_{3}$ and the timing resistors $\mathrm{R}_{5}$ and $\mathrm{R}_{6}$ of the $35 \mathrm{kHz}$ timing circuit and other associated components were connected similar to that of Fig. $4 \mathrm{a}$. The trigger and threshold inputs (pins 2 and 6) are connected together and to the timing capacitor $\mathrm{C}_{3}$ of the $35 \mathrm{kHz}$ timing circuit. The result of this connection is a continuous stream of 35,000 rectangular pulses in one second at pin 3, the output terminal of $\mathrm{IC}_{3}$. The $35 \mathrm{kHz}$ oscillator circuit is shown in Fig. 4b. The period of oscillation can be calculated using equation (3) and substituting the obtained values with $R_{5}, R_{6}$ and $C_{3}$ gives the value of the period of oscillation of the device as $28 \times 10^{-6}$ seconds.

\subsection{Frequency Selection Section}

The function of this section is to select between the output of the 25 and $35 \mathrm{kHz}$ oscillator at stipulated intervals. The essence is to introduce a measure of variability into the ultrasound signal. This is necessary to delay habituation as stated in the design considerations [5]. As the weaver birds try to adapt to the $25 \mathrm{kHz}$ sound, it switches over to $35 \mathrm{kHz}$ and vice versa. The cycle of frequency selection continues uninterrupted until the device trips off for the day. The circuitry of this section again comprises majorly of the $555 \mathrm{IC}\left(\mathrm{IC}_{4}\right)$, but this time operating in the monostable mode and used as a relay driver; that is, as an electronic switch which toggles the relay between two extremes. By so doing, it intermittently connects the output of one oscillator while disconnecting the output of the other and in the next toggle reconnects the former while disconnecting the later. Fig. 5 shows the frequency selection circuit design.

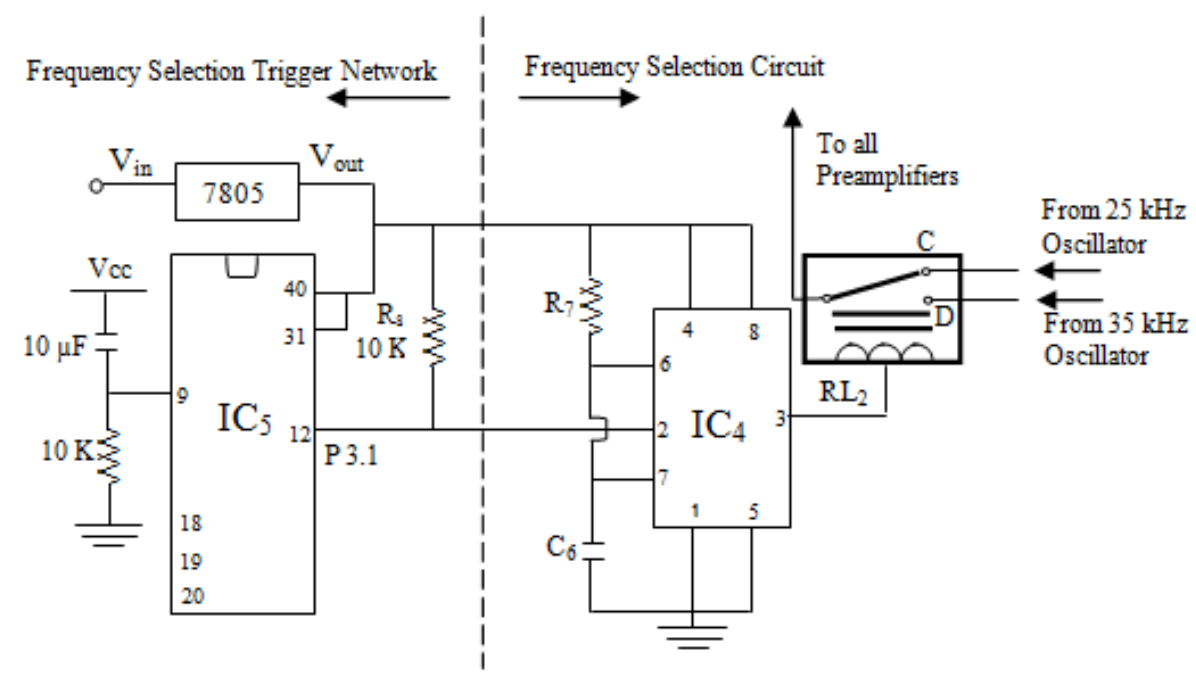

Fig.5. Frequency Selection Circuit 
For a 555 timer connected in a monostable mode and shown on the right hand side of Fig. 5., an external source of trigger is required. For this work, the external source of trigger was found in the microcontroller AT89C52 ( $\left.\mathrm{IC}_{5}\right)$ shown on the left hand side of Fig. 5., where the trigger input of the timer is linked with port 3.1 (pin 12) of the microcontroller. The period, t, taken for a monostable 555 timer to change state and back can be calculated from the design equation:

$$
t=1.1(R \times C)
$$

This is modified as:

$$
t=1.1\left(R_{7}+C_{6}\right)
$$

The duration of the intended output pulse of the 555 timer is 15 seconds while a choice of $10 \mu \mathrm{F}$ was made for the timing capacitor. From equation (5), $\mathrm{R}_{7}$, the timing resistor was calculated as $1.3 \mathrm{M} \Omega$. The 555 timer $\left(\mathrm{IC}_{4}\right)$ is triggered into operation by the microcontroller $\left(\mathrm{IC}_{5}\right)$, to be discussed in section 6 . The frequency selection program addressed to port 3.1 (P 3.1) location of the microcontroller sends trigger pulses every thirty seconds to the 555 timers trigger input (pin 2), thereby disconnecting from one oscillator, say $25 \mathrm{kHz}$ oscillator at point $\mathrm{C}$ and establishing contact with the $35 \mathrm{kHz}$ oscillator at point $\mathrm{D}$ within a time interval of fifteen seconds. This is maintained until another fifteen seconds elapse and together making thirty seconds required for another trigger from the microcontroller. The output of the frequency selection section is taken between the $5 \mathrm{~V}$ relay's common and ground and passed to the preamplifiers of the amplification section.

\subsection{Microcontroller Section}

The AT89C52 is a $5 \mathrm{~V}$, forty pin microcontroller used for the purpose of electronic control. Once connected to factory specification as shown on the left hand side of Fig. 5. and programmed, it faithfully executes inputted instruction, up to a maximum of thirty two instructions. In this work, the microcontroller will be used to control three sections of the device. These are: the frequency selection section, the predator cry section and the visual display section. The program to be executed will be written in Assembly language and stored in specific locations for the respective sections. Once operational, it will automatically exercises control over these sections either by triggering them into operation or enabling them to execute instructions as commanded. Fig. 8 shows the interconnection between the microcontroller and the frequency selection, predator cry and the visual display section.

\subsection{Amplification Section}

Ultrasound is a short ranger, as such a design consideration termed "high Propagative Power" was presented [5]. To implement this, a powerful amplification is necessary to propel the signal so as to attain reasonable coverage. This is of utmost importance in field application. To suit the multi-directional nature of this design, the amplification section will consist of five segments. One for each direction and comprises of a preamplifier and a power amplifier.

\subsubsection{The Preamplifier}

The first stage of amplification will be achieved via the preamplifier. It boosts the already weak ultrasound to an appreciable level to be sensed by the main amplifier (power amplifier). The pre-amplifier comprises majorly 
of the most versatile Integrated Circuit available, the UR741 ( $\left.\mathrm{IC}_{6}\right)$ [15] connected in a non- inverting mode. The circuit diagram of one of the five segments of the preamplifier design connected in a non- inverting mode is shown in Fig. 6. Four others were replicated in four directions. $\mathrm{IC}_{6}(\mathrm{UR741N})$ is flexible and so allows for personalized design [17]. The gain of the IC, A is given by:

$$
A=1+\left[\frac{R_{f}}{R}\right]
$$

where $\mathrm{R}_{f}$ is the value the feedback resistor while $\mathrm{R}$ is the input resistor. Equation (7) can be modified as:

$$
A=1+\left[\frac{R_{f 1}}{R_{8}}\right]
$$

A gain of 500 was desired for the preamplifier. Therefore, a choice of $1 \mathrm{~K}$ was made for $\mathrm{R}_{8}$ and $\mathrm{R}_{f 1}$ was calculated using equation (8) to obtain the value of $499 \mathrm{~K}$. The design has a $0.1 \mu \mathrm{F}$ capacitor $\left(\mathrm{C}_{7}\right)$ at its input, to block electrical noise that may have been generated in the circuit from entering the preamplifier and another 2.2 $\mu \mathrm{F}$ capacitor $\left(\mathrm{C}_{8}\right)$ at the output. Thus, the preamplifier as designed will raise the voltage level of the ultrasound signal applied to its input by 500. The circuit diagram of the preamplifier circuit is shown in the first section of Fig. 6.

\subsubsection{Power amplification}

Power amplification was achieved using LM386 operational amplifier $\left(\mathrm{IC}_{7}\right)$. It is a low voltage power amplifier which comes in an 8-pin mini-DIP package. The IC is designed to deliver a voltage amplification of 20 without external add-on parts. But this voltage gain can be raised up to 200 by adding external parts. One of its popular applications is its usage as ultrasonic drivers (ultrasonic amplifier). A typical circuit diagram of the power amplifier design employing LM386 Op-Amp is shown in the second section of Fig. 6. This again was replicated in the five segments servicing each direction.

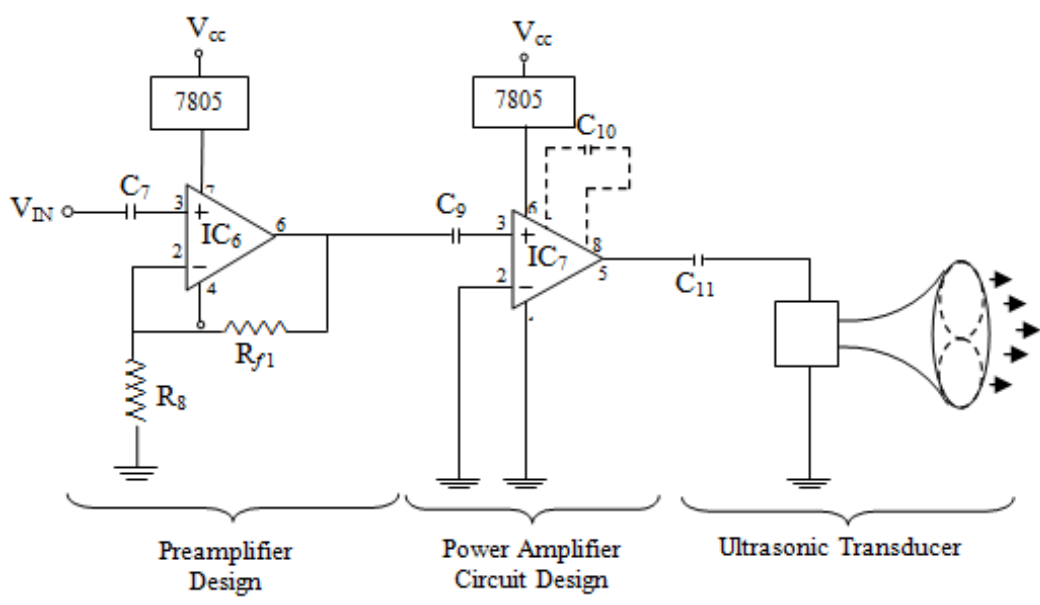

Fig.6. Booster Preamplifier, Amplifier and Ultrasonic Transducer Design in One of the five Directions 
The power amplifier's input signal is the pre-amplifiers output signal. In order to obtain a higher gain from the IC, the circuit is moderated between pin 1 and pin 8 . According to the theory behind the IC [17], to obtain the maximum gain of 200 , a $10 \mu \mathrm{F}$ capacitor should be connected across pin 1 and 8 . Therefore, a $10 \mu \mathrm{F}$ capacitor $\left(\mathrm{C}_{10}\right)$ was connected across pin 1 and 8 (in dotted lines) to guarantee a gain of 200 as shown in Fig. 6. This stage has $0.1 \mu \mathrm{F}$ capacitor $\left(\mathrm{C}_{9}\right)$ to filter out noise in the incoming signal that might have also been pre amplified. The total gain of the amplification section is given by the product of the preamplifier gain and the power amplifier gain. That is,

$$
\text { Total Gain }=(\text { Preamplifier Gain }) \times(\text { Power Amplifier Gain })=100,000
$$

This simply means that the device's amplifier has been able to raise the voltage level of the ultrasound signal generated by the device's oscillators by one hundred thousand times. With this level of amplification, the ultrasound will propelled to penetrate deeper into the air and saturate the vicinity of broadcast to a reasonable distance.

\subsection{Ultrasonic Transducer Section}

An ultrasonic transducer is a device used to convert other types of energy into an ultrasonic vibration or vice versa [19]. In this case, it is a means of converting the ultrasonic frequency signal so generated by the oscillator and energized by the power amplifier into an ultrasonic sound (ultrasound). To do this, piezoelectric transducers are employed. In this work, five low-cost, high-frequency dual diaphragm dual outlet type piezoelectric tweeter operating at $4-45 \mathrm{kHz}$ each are employed. The tweeter plays unique roles of not only converting the high frequency electrical signal generated by the oscillator and amplified by the amplifiers into sound (ultrasound), but also transmitting (or broadcasting) same. Ultrasound is unidirectional by nature, therefore four units of ultrasonic transducers positioned $90^{\circ}$ sideways, and a fifth positioned $90^{\circ}$ downward were used. This is to ensure $360^{\circ}$ horizontal coverage and a vertical boost. The schematic diagram of the ultrasonic transducer section is shown in part of Fig. 6. The inputs to each of the five ultrasonic transducers were tapped from each of the five power amplifiers output and ground respectively. The ultrasonic transducers serve as the load on each segment of the amplification section. Coupling to the ultrasonic transducer was done with a $220 \mu \mathrm{F}$ capacitor, $\mathrm{C}_{11}$.

\subsection{Predator Cry Section}

Observation during the field survey [10], reveals that certain animals are predators to the weaver birds and their cry can be used as a local pest control method. Such sound alone can scare the birds from a distance. This section was introduced to improve the bird scaring effect of the device. It is aimed at incorporating an audio component to complement the hitherto ultrasonic (inaudible) component, especially after habituation is noticed to gradually creep in. An audio voice recording chip with a 60 seconds recording period was used. Voice and audio signals were stored directly into memory in their natural form providing high fidelity voice reproduction. The ISD2560 $\left(\mathrm{IC}_{8}\right)$ was used to program the frightening and attacking cry of some approaching weaver bird predators. The dreaded hawk, dog and man were identified as common predators. Also, the distressed cry of weaver birds under predator attack was also captured. This improves the bird-scaring effect of the device as the intermittent cry introduces a measure of variability into the transmitted signal which is an antidote for habituation [6]. To sounds of the predators are first recorded with an audio recorder and finally recorded into the IC. Both the microcontroller and ISD2560 are linked via port 3.0 (pin 11) and port 3.1 (pin 10) of the microcontroller and pin 27 and pin 23 of the ISD2560. Fig. 7 shows the circuit connection of the ISD in mode 4 which permits skipping between recorded tracks. Its $5 \mathrm{~V}$ requirement is guaranteed via the use of voltage regulator, the 7805 . 


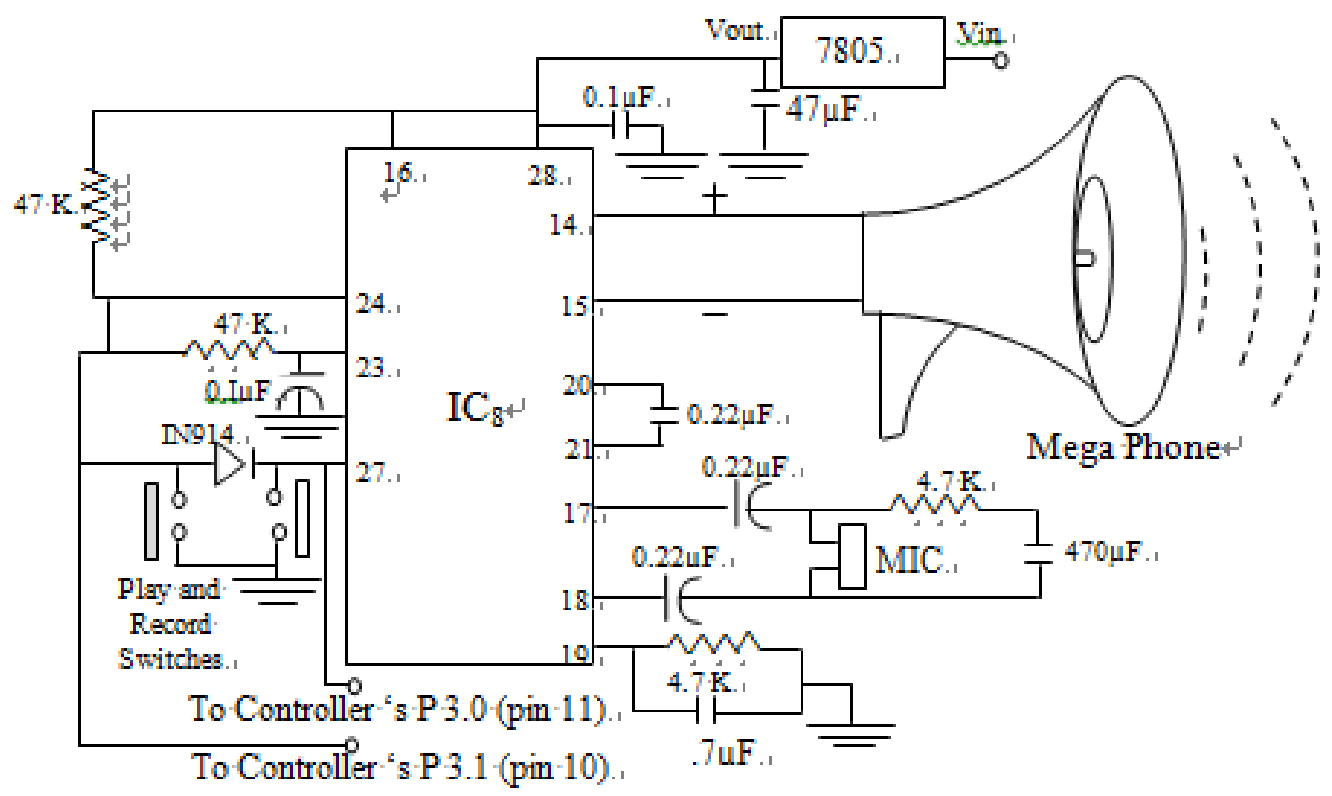

Fig.7. Circuit Connection of ISD2560

The output of the ISD is interfaced with an external speaker to relay a selected predator cry. In this work, a megaphone is used as the speaker. The megaphone is independently powered by a $6 \mathrm{~V}$ battery and has a 15 Watt in-built amplifier, $205 \mathrm{~mm}$ horn diameter and an effective coverage distance of 600 metres.

\subsection{Visual Display Section}

An electronic visual display of the current frequency and predator cry is implemented with a sixteen by two (16 x 2) segment Liquid Crystal Display (LCD). The device communicates with users visually using this display. As stated earlier, this section is controlled by the same microcontroller AT89C52 of the microcontroller section. Pin 7 to pin 14 (DB ports) of the LCD are connected to port 0 (pins 32 to 39) of the microcontroller as shown in Fig. 8. The $100 \mathrm{~K}$ variable resistor on pin 2 is for brightness control where it is adjusted to desired brightness, as pin 15 controls the backlight on which the information appears. A $330 \Omega$ resistor gives the desired brightness of the backlight. The $5 \mathrm{~V}$ requirement of the LCD is derived via a 7805 voltage regulator. The microcontroller's program alerts the LCD of its communication with the frequency selection unit where it displays the current broadcast frequency, be it $25 \mathrm{kHz}$ or $35 \mathrm{kHz}$ and with the ISD2560 where it displays the current predator sound selected.

\section{Result and Discussion}

The culmination of each sectional design presented in this work result to the overall circuit design and the overall circuit diagram of the solar powered ultrasonic device for the control of weaver birds in farms. The overall circuit is shown in Fig. 8. 


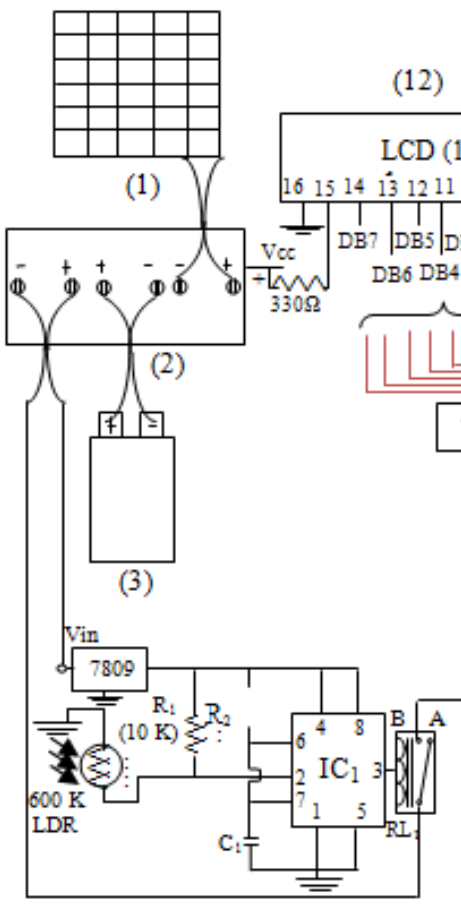

(4)
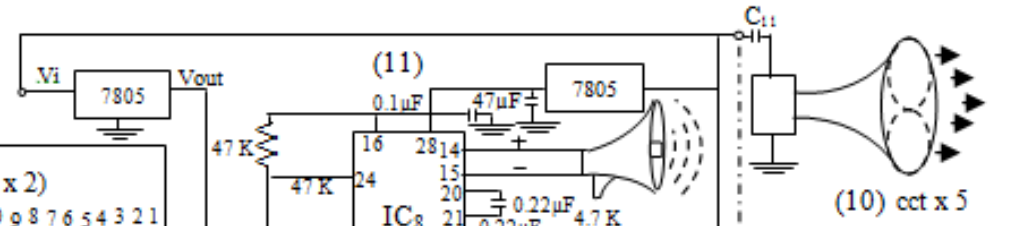

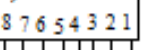
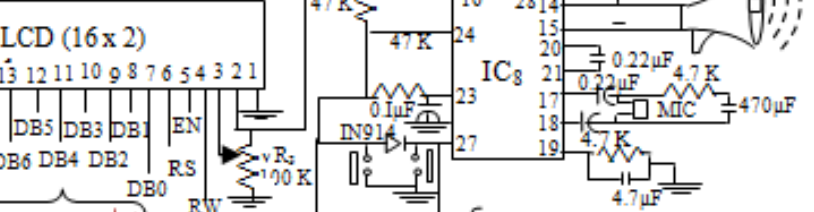

作

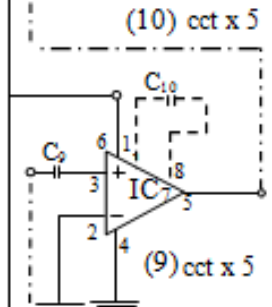

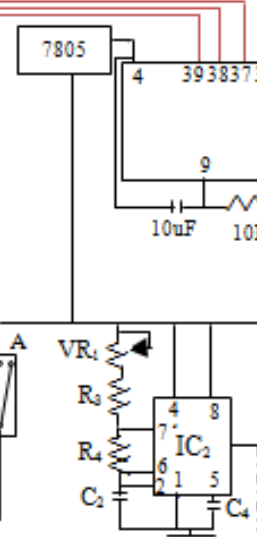

(5)
(6)
(13)

$101112 \quad 18 \quad 19 \quad 20$
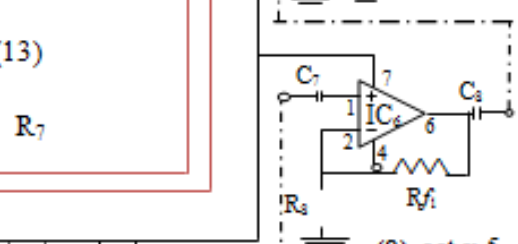

(8) $\operatorname{cct} x 5$

Fig.8. Overall Circuit Diagram of the Solar Powered Ultrasonic Device

The labelling of Fig. 8. is provided below:

1. Solar Panel

2. Charge Controller

3. Battery

4. Tripping Circuit

5. $25 \mathrm{kHz}$ Oscillator

6. $35 \mathrm{kHz}$ Oscillator

7. Frequency Selection Circuit

8. Pre-amplifier Circuit

9. Power Amplifier Circuit

10. Ultrasonic Transducer

11. Predator Cry

12. Visual Display Section

13. Microcontroller Circuit

Power Line

Ultrasonic Signal Line -......

Electronic Communication Line

The mode of operation is as follows: When the power source is activated, the device is enabled to source it's energy from the sun but will only come up at daylight to generate ultrasound signal of frequencies of 25 and 35 
$\mathrm{kHz}$ through the timing and oscillatory sections which are respectively selected at intervals of fifteen seconds. The ultrasound signals are preamplifier and then power amplified. The amplified ultrasonic signal is relayed to the ultrasonic transducer for conversion to ultrasound and subsequent transmission to deter weaver birds within the location with a $360^{\circ}$ horizontal spread and a vertical boost. Electronic control and sequencing over the sections is achieved via the microcontroller section which is able to trigger selected programmed predator sounds to audible level to further fortify the device in times of habituation.

Fig. 9 shows the simulation result of the output characteristics of the propose device in terms of output signal frequency and operating time. It can be inferred from the figure that the output is a continuous stream of intermittent $25 \mathrm{kHz}$ and $35 \mathrm{kHz}$ high intensity ultrasound signal.

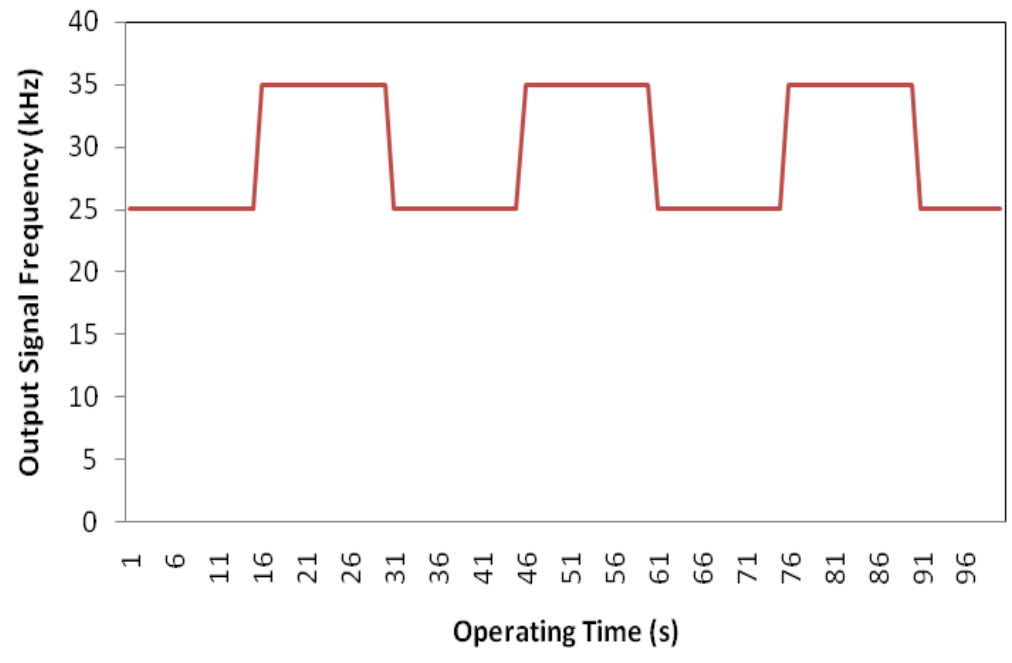

Fig.9. Output-Time Characteristics of Design Simulation

The cycle of frequency changes in every 15 seconds gives credence to the frequency selection circuit for the implementation of the concept of variability as an antidote to habituation. As the weaver birds try to adapt to the worrying effect of the $25 \mathrm{kHz}$ sound, it switches over to $35 \mathrm{kHz}$ and vice versa. This inconveniencing stimulus is believed to trigger a behavioural change of abstinence from the vicinity of broadcast. The cycle of frequency selection continues uninterrupted until the device trips off for the day as controlled by the Light/Photo Dependent Resistor (L.D.R).

The design as presented covers all aspects of the conventional second (most recent) generation ultrasonic pest control devices [20] and beyond, in the sense that it is solar powered, pest specific, environmental specific, field/farm adapted, dual frequency, high penetrating power and multi-directional in effect. Other design questions such as the casing design, support/stand design and details of the microcontroller's program codes and its operational flowchart shall be presented at the implementation stage when facts such as the sizes of the circuit board and other peripherals will be major determinants.

\section{Conclusion and Future Scope}

The outcome of an expanded field survey has served as a precursor for this optimal circuit design. Using robust design considerations, design calculations and analysis supported by circuit diagrams, a dynamic ultrasonic pest control device that is unique was arrived at. The absence of field survey has been the missing 
link, with this gap filled and a design in place; the stage is set for the implementation and testing of a more effective solar powered ultrasonic weaver bird pest control gadget which can withstand the challenge of weaver bird pests infestation, especially by checking habituation which has been a major factor behind the inefficiencies of earlier designs.

\section{References}

[1] Hangiandreou, J. Physics Tutorial for Residents: Topics in US: B-mode US: Basic Concepts and New Technology. Radiographics. 2003; 23 (4), 1019.

[2] Deepali, G., Balwinder, S., Harpreet, S. Design and Development of Pesticide Residue Detection System using EC and pH Sensor. International Journal of Engineering and Manufacturing (IJEM), Vol.6, No.2, pp.10-17, 2016.DOI: 10.5815/ijem.2016.02.02.

[3] Victor, P. Rodent Repellents. http://www.victorpest.com/advice/all-about/victor-repellents/types-ofrepellents. Retrieved 2009-10-22.

[4] Subramanyam, B. Ultrasound and Arthropod Pest Control: Hearing is Believing! (pdf). Kansas State University; 2001.

[5] US FTC. Analysis of Proposed Consent Order to Aid Public Comment In the Matter of Global Instruments Ltd., and Charles Patterson". Federal Trade Commission; 2003.

[6] Ibrahim, A.G., Oyedum, O.D., Awojoyogbe, O.B., Okeke, S.S.N. Electronic Pest Control Devices: Their Necessity, Controversies and Design Considerations. The Int. J. Engr \& Sci., 2013; 2(9) 26-30.

[7] Ibrahim, A.G., Oyedum, O.D., Awojoyogbe, O.B., Okeke, S.S.N. Developmental Features and Implementation Challenges of Electronic Pest Control Devices in Developing Countries. Int. J. Sci. \& Engr. Res.2014; 5(2) 411- 416.

[8] Ibrahim, A.G., Oyedum, O.D., Awojoyogbe, O.B., Okeke, S.S.N. Ultrasound Investigation for determining the suitability of Ultrasonic Pest Control Devices on target pests in Specific Location using Bird Flight Data. A Case Study of Weaver Birds in Doko Community, Niger State, Nigeria. The Int. J. Engr. \& Sci; 2015. In Press.

[9] Ibrahim, A.G. Development and Performance Evaluation of a Solar Powered Ultrasonic Device for the Control of Weaver Birds in Farms. A Ph.D Thesis, Department of Physics, Federal University of Technology, Minna, Nigeria; 2015.

[10] Ibrahim, A.G., Oyedum, O.D., Awojoyogbe, O.B., Ezenwora, J.A and Aje, J.D. Pest and Environmental Specific Application of Ultrasound in Pest Control. Advances in Multidisciplinary and Scientific Research, 2016; 2(4) 189 - 200.

[11] Grob, B., Mitchel, E.S. Basic Electronics, nineth ed. Glencoe/McGraw-Hill, Columbus; 2003.

[12] Ezenwora, J.A. Development and Performance Evaluation of a Power System Based on the Characterisation and Performance Evaluation of P-V System in Minna, Niger State, Nigeria. A Ph.D Thesis, Department of Physics, Federal University of Technology, Minna, Nigeria; 2016.

[13] Oyedum, O.D., Ugwoke, P.E., B.M Olomiyesan, B.M., Ibrahim, A.G. Performance Evaluation of Polycrystalline Silicon Module under outdoor conditions in North Central, Nigeria. Nig. J. Phy., Special Edition, 2014; 37-42.

[14] Ojeniyi, M.O. Urban Expansion and Environmental Impact in Minna Metropolis. M.Sc Thesis, Geography Department, Bayero University, Kano, Nigeria. 2014.

[15] Tony, V., 2010. LM555 and LM556 Timer Circuits, Doctronics Williams Lab. Retrieved 15/7/ 2010 from http://www.matni.com/Arabic/Elec.../NE555\%20DETAILS/555.html

[16] Ryan, V. The 741 Operational Amplifier. (2009). Retrieved 17/9/ 2011 from http://www.technologystudent.com.

[17] Usifo, O., Research Project Implementation Made Ease, first Edition. ECAS Ltd, Nigeria; 2004. 
Control Device for Field Applications

[18] National Semi-conductor Data sheet LM 386. www.alldatasheet.com/datasheetpdf/pdf/9027/NSC/LM741.html

[19] Encyclopædia Britannica. Ultrasonic Transducer. Ultimate Reference Suite Chicago; (2010).

[20] Khapare, N.K., P.S. Bodke, P.S., Khapare, K.N. Development, Performance and Evaluation of Ultrasonic Pest and Insect Repelling System. Int. J. Engr. Res. \& Gen. Sci. 2015; 3(2) 19-25.

\section{Authors' Profiles}

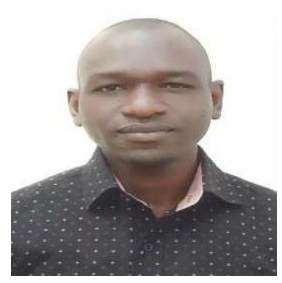

Aku Godwin Ibrahim - Obtained his Ph.D from the Federal University of Technology, Minna, Nigeria in 2015. He received his Masters and Bachelors degree from the University of Agriculture, Makurdi, Nigeria, and University of Jos, Nigeria in 2006 and 2002 respectively. He is currently a Senior Lecturer at the department on Physics, Federal University of Technology, Minna, Nigeria. His primary research interests are in the area of Physics Electronics and Communication/Atmospheric Physics.

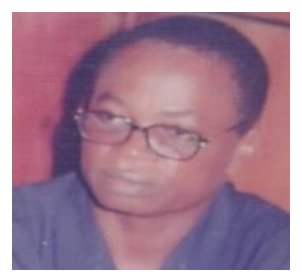

Onyedi David Oyedum - Obtained his Bachelor's Degree in 1977 from The University of Nigeria, Nsuka. His Masters Degree was obtained from The Ahmadu Bello University, Zaria, Nigeria in 1982 and Ph.D from The Federal University of Technology, Minna, Nigeria in 2005. He is serving as a Professor in the department of Physics, Federal University of Technology, Minna, Nigeria. His research interests are in the area of Communication/Atmospheric Physics and Physics Electronics.

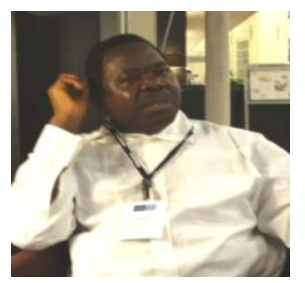

Omotayo Bamidele Awojowogbe - Received his B.Sc degree in Physics and Engineering Physics from the Ondo State University, Ado Ekiti (now University of AdoEkiti), Nigeria in 1987, M.Sc in Theoretical Physics, University of Ibadan, Nigeria in 1991 and PhD from Federal University of Technology Minna, Nigeria. In collaboration with the Institute of Biomedical Engineering and Medical informatics, Swiss Federal Institute of Technology (ETH Zurich) and the University of Zurich, in 1997. He won the 2003 Young African Mathematician Medal Award by African Mathematical Union at the International Conference of Mathematical Sciences (AMU-ICMS).

He is a professor of Physics in the department of Physics, Federal University of Technology, Minna, Nigeria and an assosiate member of the Abdul Salam International Centre for Theoretical Physics (ICTP), Trieste, Italy. His field of research is Theory, Dynamics and Applications of the analytical solutions of the Bloch NMR flow equations.

How to cite this paper: A.G Ibrahim, O.D Oyedum, O.B Awojowogbe,"Design Description of a Stand-Alone, Auto-Frequency Ultrasonic Brand of Weaver Bird Pest Control Device for Field Applications", International Journal of Engineering and Manufacturing(IJEM), Vol.7, No.5, pp.1-15, 2017.DOI: 10.5815/ijem.2017.05.01 